\title{
Serum Cytokeratin 18-Asp396 as an Early Predictor of Acute Paracetamol Hepatotoxicity
}

\author{
Mohemmed A.M. Khalaf, Hefnawy A.A and Mostafa Abolhamd ${ }^{1}$
}

${ }^{1}$ Departments of Forensic Medicine and Clinical Toxicology- Faculty of Medicine, Minia University, Minia, Egypt.

\begin{abstract}
Paracetamol is a well-known hepatotoxic drug in acute overdose. Early assessment of the severity of acute paracetamol toxicity still a problem. Serum Cytokeratin 18-Asp396is a novel biomarker that reflects the degree of liver damage.This study was carried out to investigate that Cytokeratin 18Asp396can represent an early and valuable predictor of pre-clinical and clinical acute paracetamol toxicity in humans. The clinical work was conducted at Minia PCC during the period from January, 1st, 2011 to December, 31th, 2015 where 127 adult patients with a history of paracetamol overdose from whom 84 patients had confirmed to have acute paracetamol toxicity, were received.All subjects were investigated for serum paracetamol level 4 hours post-ingestion and for liver function tests (ALT, AST, ALP andtotal bilirubin) and Cytokeratin 18-Asp396 at 4, 24, 36, and 48 hours post-ingestion.The results of the current study revealed that all investigated liver function tests including ALT, AST, ALP and bilirubin started to be increased with statistically significant values 24 hours post-ingestion, reached a peak after 36 hours, and started to decline after 48 hours. On the other hand it has been found that Cytokeratin 18-Asp396 values were increased significantly 4 hours post-ingestion, when compared to mean value of healthy volunteers, reached a peak after 36 hours, and started to decline after 48 hours. The results reflects the earlier effects of paracetamol toxicity on Cytokeratin 18-Asp396 serum level than the other measured liver function tests. Accordingly, Cytokeratin 18-Asp396 serum level could be considered a promising predictor for early diagnosis of pre-clinical and clinical acute paracetamol toxicity in humans. Further studies are recommended to assess its sensitivity and specificity as a predictor for early diagnosis of acute Paracetamol-induced hepatotoxicity.
\end{abstract}

Keywords Paracetamol, Cytokeratin 18-Asp396, Liver function tests, Hepatotoxicity.

\section{Introduction}

A cetaminophen aminophenol; APAP) is widely usedAPAP) is widely used as analgesic and antipyretic drug worldwide. It produces alanine derivatives by hydrolysis, which are directly converted into hydroxylamine.

N-Acetyl-pbenzoquinoneimine (NAPQI) is an intermediate product of acetaminophen produced in the presence of cytochrome-p450 that causes hepatic damage both in humans and experimental animals (Soundharrajan et al., 2016).

Caspase-cleaved cytokeratin 18 (CK18-Asp396) is released from hepatocytes during apoptosis. In apoptotic cell death, intermediate filament protein cytokeratin 18 (CK18) is cleaved by caspases at Asp396 and the product (M30 antigen) may be specifically detected by the monoclonal antibody M30. In this regard, a growing body of evidence clearly indicates that levels of CK18-Asp396 may be used as a surrogate biomarker of apoptotic cell death (Ueno et al., 2003andYagmur et al., 2007).

As hepatic injury generally starts 24 to 72 hours after paracetamol ingestion with marked elevations in serum ALT and AST (http://livertox.nih.gov/Acetaminophen.ht $\mathrm{m})$, the current study was conducted to investigate that Cytokeratin 18-Asp396 can represent an early and valuablepredictor of preclinical and clinical acute paracetamol-induced hepatotoxicity in human.

\section{Subjects and Methods Subjects}

Our study involved 84 subjects of both sexes. 


\section{Clinical protocol.}

The clinical work was conducted at Minia Poison Control Center (PCC) during the period from January, 1st, 2011 to December, 31th, 2015 where 127 adult patients with a history of paracetamol overdose were received. From whom 84 patients had confirmed to have acute paracetamol toxicity. All subjects received the usual treatment including methods of elimination (Emesis, activated charcoal, $\mathrm{N}$ acetyl cysteine as antidote therapy)

\section{Exclusion criteria}

All subjects with a delay time more than 4 hours after paracetamol ingestion,or subjects had history of concomitant administration of another $\operatorname{drug}(\mathrm{s})$, systemic diseases, bilharziasis, hepatitis, or malignancies were excluded from the study.

\section{Human rights}

All followed procedures were in accordance with the ethical standards of the Medical Ethical Committee at National Research Centre, Cairo, Egypt and with the Helsinki Declaration of 1975 , as revised in 2008. Informed consent was obtained from all patients for being included in this study. Confidentiality of records is saved by keeping the records anonymous.

\section{Blood collection and separation.}

After taking their written consents, venous blood samples $(5 \mathrm{ml})$ were drawn from the patients, were kept into a clean dry centrifuge tubes and left to stand for few hours before centrifugation to avoid hemolysis. Serum was separated.

\section{Serum Biochemical Analysis.}

All subjects were investigated for serum paracetamol level 4 hours post-ingestion to confirm intoxication and for liver function tests (ALT, AST, ALP, and bilirubin) and Cytokeratin 18-Asp396 at 4, 24, 36, and 48 hours post-ingestion.

Paracetamol serum level: measured by colorimetric method according to Glynn and Kendal (1975). Paracetamol level above $150 \mu \mathrm{g} / \mathrm{ml}, 4$ hours post-ingestion, indicates possible acute paracetamol-induced hepatotoxicity.

Liver function tests: Alanine transferase and Aspartate transferase (ALT and AST): were measured spectrophotometrically using Spekol II Carl-Zeiss spectrophotometer (Reitman and Frankel, 1957) and (Kind and King, 1954). Serum alkaline phosphatase level (ALP.), measured by colorimetric method according to Donald \& Ralph, (1993). Serum total bilirubin level (T. Bil) measured according to Suber, (1994). Laboratory references for ALT (0-40U/l), AST (0-40U/l), $\operatorname{ALP}(<128 \mathrm{U} / \mathrm{l})$ and T.Bil (0.3-1.2 mg/dl).

CK18-Asp396 (M30 ELISA) in

Blood: Serum levels of CK18-Asp396 were determined by commercially available immunoassays (M30Apoptosense ELISA kit, Peviva AB, Bromma, Sweden) according to the manufacturer's protocol. In brief, samples were placed into wells coated with a mouse monoclonal antibody as a catcher. After washing, a horseradish peroxidaseconjugated antibody (M30) was used for detection. Reference concentrations of CK18-Asp396 were used to prepare assay calibration. The absorption was determined with an ELISA reader at 450 nm. Inter- and intra-assay coefficients of variation were below 10\%. Concentrations of CK18-Asp396 were expressed in units per liter (U/l) according to the manufacturer's instructions. Plasma CK18-Asp396 levels within 20 normal healthy volunteers were assessed using the M30 Apoptosense ELISA. Within the population studied there was a wide range of values, from 57 to $862 \mathrm{U} / \mathrm{l}$, with a mean of $121 \pm 46 \mathrm{U} / \mathrm{l}$. This value was considered as the laboratory control which compared with the other results of the different post-ingestion periods. The values were independent of age and gender.

\section{Statistical analysis}

The collected data was organized, tabulated and statistically analyzed using SPSS software statistical computer package version 17. Data were expressed as Mean \pm Standard Deviation (SD). Paired sample-t test was used to differentiate between two means where probability $(\mathrm{P}) ; \mathrm{P}<0.05$ : was considered significant. Correlations were estimated using Pearson's test where probability $(\mathrm{P}): \mathrm{P}<0.05$ was considered significant.

\section{Results}

Fromthe 127 adult patients with a history of paracetamol overdose and with a delay time not more than 4 hours, only 84 patients had been confirmed to have acute paracetamol toxicity according to Rumack-Mattew nomogram (Rumack and Mattew, 1975). There was a wide range $(157.12-313.27 \mu \mathrm{g} / \mathrm{ml})$ with a mean \pm S.D of $(187.47 \pm 23.11 \mu \mathrm{g} / \mathrm{ml})$, which indicated the possibility of acute paracetamolinduced hepatotoxicity.

The results of the current study revealed that all investigated liver function tests including ALT, AST, ALP and bilirubin started to be increased with statistically significant values after 24 hours post-ingestion, reached a peak after 36 hours, and started to decline after 48 hours. On the other hand it has been found that Cytokeratin 18-Asp396 values were increased significantly 4 hours postingestion (765.38 $\pm 122.14 \mathrm{U} / \mathrm{l})$ when compared to mean values of healthy volunteers 
that was $121 \pm 46 \mathrm{U} / \mathrm{l}$, reached a peak after 36 hours, and started to decline after 48 hours (Table 1 and Figs. 1, 2 \& 3).

Table 2 shows ALT values (U/l) as mean+ S.D of acute paracetamol intoxicated patients at different hours post-ingestion. There was significant statistical elevation of ALT values at $24 \mathrm{hrs}, 36 \mathrm{hrs}$ and 48 hrs postingestion when compared to ALT value 4 hrs post-ingestion. Also, there was significant statistical elevation of ALT values at $36 \mathrm{hrs}$ and 48 hrspost-ingestion when compared to ALT value 24 hrs post-ingestion. In addition, there was significant statistical elevation of ALT value 48 hrspost-ingestion when compared to ALT value 36 hrs post-ingestion.

Table 3 shows AST values (U/l) as mean+ S.D of acute paracetamol intoxicated patients at different hours post ingestion. There was significant statistical elevation of AST values at 24hrs, $36 \mathrm{hrs}$ and 48 hrs postingestion when compared to AST value 4 hrs post-ingestion. Also, there was significant statistical elevation of AST values at 36 hrs and 48 hrspost-ingestion when compared to AST value 24 hrs post-ingestion. In addition, there was significant statistical elevation of AST value 48 hrspost-ingestion when compared to AST value 36 hrs post-ingestion.

Table 4 shows ALP values (U/l) as mean+ S.D of acute paracetamol intoxicated patients at different hours post-ingestion. There was significant statistical elevation of ALP values at 24hrs, 36 hrs and 48 hrs postingestion when compared to ALPvalue $4 \mathrm{hrs}$ post-ingestion. Also, there was significant statistical elevation of ALP values at $36 \mathrm{hrs}$ and 48 hrspost-ingestion when compared to ALPvalue 24 hrs post-ingestion. In addition, there was significant statistical elevation of ALP value 48 hrspost-ingestion when compared to ALPvalue 36 hrs postingestion.All of the above elevations were of statistical significance only because ALPvalues at different post-ingestion periods were in the normal laboratory range.

Table 5 shows Bilirubin values $(\mathrm{mg} / \mathrm{dl})$ as mean+ S.D of acute paracetamol intoxicated patients at different hours postingestion. There was significant statistical elevation of Bilirubin values at 24hrs, $36 \mathrm{hrs}$ and 48 hrs post-ingestion when compared to Bilirubinvalue 4 hrs post-ingestion. Also, there was significant statistical elevation of Bilirubin values at 36 hrs and 48 hrspost-ingestion when compared to Bilirubinvalue 24 hrs postingestion. In addition, there was significant statistical elevation of Bilirubin value 48 hrspost-ingestion when compared to Bilirubinvalue 36 hrs post-ingestion.

Table 6 shows Cytokeratin 18Asp396 (CK18-Asp39)values (U/l) as mean+ S.D of acute paracetamol intoxicated patients at different hours post-ingestion. There was significant statistical elevation of CK18Asp39values at 24hrs, 36 hrs and 48 hrs postingestion when compared to CK18-Asp39 value 4 hrs post-ingestion. Also, there was significant statistical elevation of CK18-Asp39 values at 36 hrs and 48 hrsafter admission when compared to CK18-Asp39 value 24 hrs post-ingestion. In addition, there was significant statistical elevation of CK18-Asp39 value 48 hrspost-ingestion when compared to CK18-Asp39 value 36 hrs post-ingestion.

Correlations between mean of paracetamol level and ALT, AST, ALP, bilirubin and CK18-Asp39 values, 4 hours post-ingestion,were shown in table 7 and figs. 4, 5, 6, 7, 8. Positive insignificant correlations were observed betweenparacetamol level and ALT, AST \& bilirubin values. Negative insignificant correlation was observed betweenparacetamol leveland ALP values.Positive significant correlation was observed betweenparacetamol level and CK18ASP396 i.e. the increase in paracetamol level is associated withincrease in CK18-ASP396 value.

Table (1): Values of ALT, AST, ALP, Bilirubin, and CK18-Asp396 of acute paracetamol intoxicated patients at different hours post-ingestion expressed as (Mean + S.D).

\begin{tabular}{|c|c|c|c|c|c|}
\hline \multirow{2}{*}{$\begin{array}{c}\text { Time } \\
\text { (Hrs) }\end{array}$} & \multicolumn{5}{|c|}{ Parameter } \\
\cline { 2 - 6 } & $\begin{array}{c}\text { ALT } \\
(\mathrm{U} / \mathrm{l})\end{array}$ & $\begin{array}{c}\text { AST } \\
(\mathrm{U} / \mathrm{l})\end{array}$ & $\begin{array}{c}\text { ALP } \\
(\mathrm{U} / \mathrm{l})\end{array}$ & $\begin{array}{c}\text { Bilirubin } \\
(\mathrm{mg} / \mathrm{dL})\end{array}$ & $\begin{array}{c}\text { CK18-Asp396 } \\
(\mathrm{U} / \mathrm{l})\end{array}$ \\
\cline { 2 - 6 } & Mean \pm S.D & Mean \pm S.D & Mean \pm S.D & Mean \pm S.D & Mean \pm S.D \\
\hline 4 & $28.89 \pm 6.31$ & $27.52 \pm 5.71$ & $19.22 \pm 3.93$ & $0.6 \pm 0.21$ & $765.38 \pm 122.14$ \\
24 & $167.23 \pm 16.47$ & $156.36 \pm 12.62$ & $76.22 \pm 7.36$ & $1.36 \pm 0.46$ & $986.24 \pm 144.21$ \\
36 & $212.65 \pm 23.19$ & $209.23 \pm 19.27$ & $98.43 \pm 9.17$ & $1.68 \pm 0.73$ & $1213.234 \pm 234.67$ \\
48 & $116.36 \pm 12.38$ & $103.18 \pm 9.53$ & $65.29 \pm 6.39$ & $1.43 \pm 0.57$ & $828.109 \pm 123.91$ \\
\hline
\end{tabular}


Table (2): Paired sample-t test analysis of ALT values (U/I) of acute paracetamol intoxicated patients at different hours post-ingestion.

\begin{tabular}{|c|c|c|c|c|c|c|c|c|}
\hline t & \multicolumn{2}{|c|}{$4 \mathrm{hrs}$} & \multicolumn{2}{|c|}{24 hrs } & \multicolumn{2}{|c|}{36 hrs } & \multicolumn{2}{|c|}{48 hrs } \\
\hline \multirow{2}{*}{ ALT (M+S.D) } & \multicolumn{2}{|c|}{$28.89 \pm 6.31$} & \multicolumn{2}{|c|}{$167.23 \pm 16.47$} & \multicolumn{2}{|c|}{$212.65 \pm 23.19$} & \multicolumn{2}{|c|}{$116.36 \pm 12.38$} \\
\hline & $t$ & $\mathbf{P}$ & $t$ & $\mathbf{P}$ & $t$ & $\mathbf{P}$ & $t$ & $\mathbf{P}$ \\
\hline 4hrs & - & - & & & & & & \\
\hline 24hrs & 71.9 & $<0.001^{*}$ & - & - & & & & \\
\hline $36 \mathrm{hrs}$ & 14.6 & $<0.001^{*}$ & 14.8 & $<0.001^{*}$ & - & - & & \\
\hline 48hrs & 22.6 & $<0.001^{*}$ & 22.9 & $<0.001 *$ & 33.6 & $<0.001^{*}$ & - & - \\
\hline
\end{tabular}

$A L T=$ alanine transferase, $h r=$ hour, $(M+S . D)=$ mean value \pm standard deviation, $t=t$ value, $p=p$ value, * significant when $p$ value $<0.05$.

Table (3): Paired sample-t test analysis of AST values (U/I) of acute paracetamol intoxicated patients at different hours post-ingestion.

\begin{tabular}{|c|c|c|c|c|c|c|c|c|}
\hline & \multicolumn{2}{|c|}{$\mathbf{4}$ hrs } & \multicolumn{2}{c|}{$\mathbf{2 4}$ hrs } & \multicolumn{2}{c|}{36 hrs } & \multicolumn{2}{c|}{$\mathbf{4 8}$ hrs } \\
\hline AST (M+S.D) & \multicolumn{2}{|c|}{$27.52 \pm 5.71$} & \multicolumn{1}{c|}{$156.36 \pm 12.62$} & $209.23 \pm 19.27$ & $103.18 \pm 9.53$ \\
\hline & $\boldsymbol{t}$ & $\mathbf{P}$ & $\boldsymbol{t}$ & $\mathbf{P}$ & $\boldsymbol{t}$ & $\mathbf{P}$ & $\boldsymbol{t}$ & $\mathbf{P}$ \\
\hline 4hrs & - & - & & & & & & \\
$24 \mathrm{hrs}$ & 85.2 & $<0.001^{*}$ & - & - & & & & \\
$36 \mathrm{hrs}$ & 82.9 & $<0.001^{*}$ & 21 & $<0.001^{*}$ & - & - & & \\
48hrs & 62.4 & $<0.001^{*}$ & 30.8 & $<0.001^{*}$ & 45.2 & $<0.001^{*}$ & - & - \\
\hline
\end{tabular}

AST = aspartate transferase, $(M+S . D)=$ mean value \pm standard deviation, $t=t$ value, $p=p$ value, * significant when $p$ value $<0.05$.

Table (4): Paired sample-t test analysis of ALP values (U/I) of acute paracetamol intoxicated patients at different hours post-ingestion.

\begin{tabular}{|c|c|c|c|c|c|c|c|c|}
\hline & \multicolumn{2}{|c|}{ h hrs } & \multicolumn{2}{c|}{24 hrs } & \multicolumn{2}{c|}{36 hrs } & \multicolumn{2}{c|}{48 hrs } \\
\hline ALP (M+ S.D & \multicolumn{1}{|c|}{$19.22 \pm 3.93$} & \multicolumn{2}{c|}{$76.22 \pm 7.36$} & \multicolumn{2}{c|}{$98.43 \pm 9.17$} & $65.29 \pm 6.39$ \\
\hline & $\boldsymbol{t}$ & $\mathbf{P}$ & $\boldsymbol{t}$ & $\mathbf{P}$ & $\boldsymbol{t}$ & $\mathbf{P}$ & $\boldsymbol{t}$ & $\mathbf{P}$ \\
\hline 4hrs & - & - & & & & & & \\
$24 \mathrm{hrs}$ & 62.6 & $<0.001$ & - & - & & & & \\
36hrs & 72.8 & $<0.001$ & 17.3 & $<0.001$ & - & - & & \\
48hrs & 56.3 & $<0.001$ & 10.3 & $<0.001$ & 27.2 & $<0.001$ & - & - \\
\hline
\end{tabular}

$A L P=$ alkaline phosphatase, $(M+S . D)=$ mean value \pm standard deviation, $t=t$ value, $p=p$ value, $*$ significant when $p$ value $<\overline{0.05}$

Table (5): Paired sample-t test analysis of Values of Bilirubin (mg/dl) of acute paracetamol intoxicated patients at different hours post-ingestion.

\begin{tabular}{|c|c|c|c|c|c|c|c|c|}
\hline & \multicolumn{2}{|c|}{ 4 hrs } & \multicolumn{2}{c|}{ 24 hrs } & \multicolumn{2}{c|}{ 36 hrs } & \multicolumn{2}{c|}{ 48 hrs } \\
\hline Bilirubin (M+ S.D & \multicolumn{2}{|c|}{$0.6 \pm 0.21$} & \multicolumn{1}{|c|}{$1.36 \pm 0.46$} & $1.68 \pm 0.73$ & $1.43 \pm 0.57$ \\
\hline & $\boldsymbol{t}$ & $\mathbf{P}$ & $\boldsymbol{t}$ & $\mathbf{P}$ & $\boldsymbol{t}$ & $\mathbf{P}$ & $\boldsymbol{t}$ & $\mathbf{P}$ \\
\hline 4hrs & - & - & & & & & & \\
$24 \mathrm{hrs}$ & 13.8 & $<0.001$ & - & - & & & & \\
36hrs & 13 & $<0.001$ & 3.4 & 0.001 & - & - & & \\
48hrs & 12.5 & $<0.001$ & 0.88 & 0.382 & 2.47 & 0.014 & - & - \\
\hline
\end{tabular}

$(M+S . D)=$ mean value \pm standard deviation, $t=t$ value, $p=p$ value, ${ }^{*}$ significant when $p$ value $<0.05$

Table (6): Paired sample-t test analysis of CK18-Asp396values (U/I) of acute paracetamol intoxicated patients at different hours post-ingestion.

\begin{tabular}{|c|c|c|c|c|c|c|c|c|}
\hline & \multicolumn{2}{|c|}{4 hrs } & \multicolumn{2}{c|}{24 hrs } & \multicolumn{2}{c|}{36 hrs } & \multicolumn{2}{c|}{48 hrs } \\
\hline $\begin{array}{l}\text { CK18-Asp396 } \\
\text { (M+ S.D }\end{array}$ & \multicolumn{2}{|c|}{$765.38 \pm 122.14$} & \multicolumn{2}{c|}{$986.24 \pm 144.21$} & \multicolumn{2}{c|}{$1213.234 \pm 234.67$} & \multicolumn{2}{c|}{$828.109 \pm 123.91$} \\
\hline & $\boldsymbol{t}$ & $\mathbf{P}$ & $\boldsymbol{t}$ & $\mathbf{P}$ & $\boldsymbol{t}$ & $\mathbf{P}$ & $\boldsymbol{t}$ & $\mathbf{P}$ \\
\hline $4 \mathrm{hrs}$ & - & - & & & & & & \\
$24 \mathrm{hrs}$ & 10.7 & $<0.001$ & - & - & & & & \\
$36 \mathrm{hrs}$ & 15.5 & $<0.001$ & 7.55 & $<0.001$ & - & - & & \\
$48 \mathrm{hrs}$ & 3.3 & 0.001 & 7.62 & $<0.001$ & 13.3 & $<0.001$ & - & - \\
\hline
\end{tabular}

$(M \pm S . D)=$ mean value \pm standard deviation, $t=t$ value, $p=p$ value, ${ }^{*}$ significant when $p$ value $<0.05$, CK18-ASP396 = Cytokeratin 18-Asp396 
Table (7): Pearson's test shows correlation between ALT,AST, ALP, bilirubin andCK18Asp396values in acute paracetamol intoxicated patients 4 hours post-ingestion.

\begin{tabular}{|l|c|c|c|c|c|l|}
\hline \multicolumn{2}{|c|}{} & ALT & AST & ALP & Bilirubin & \multicolumn{1}{c|}{ CK18-ASP396 } \\
\hline \multirow{2}{*}{ Paracetamol } & r & 0.006 & 0.110 & -0.021 & 0.131 & 0.512 \\
\cline { 2 - 7 } & P & 0.956 & 0.319 & 0.852 & 0.235 & $<0.001^{*}$ \\
\hline
\end{tabular}

$r=$ Pearson's correlation coefficient, * significant when $p$ value $<0.05, A L T=$ alanine transferase, $A S T=$ aspartate transferase, $A L P=$ alkaline phosphatase,CK18-ASP396= Cytokeratin 18-Asp396

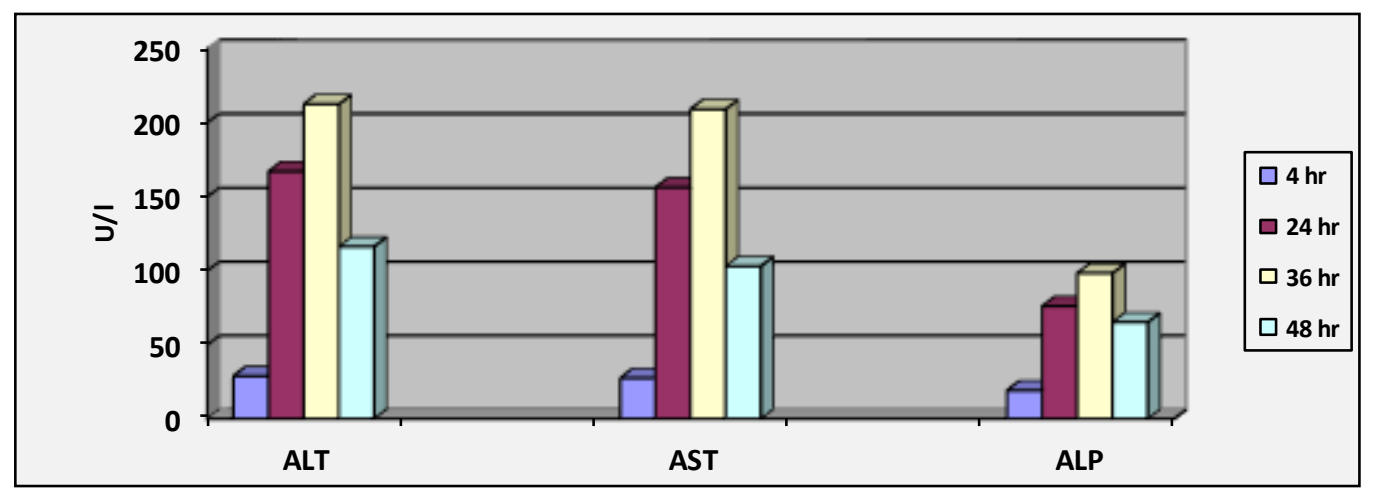

Fig. (1): Mean values of ALT, AST, ALP of acute paracetamol intoxicated patients at different hours post-ingestion.

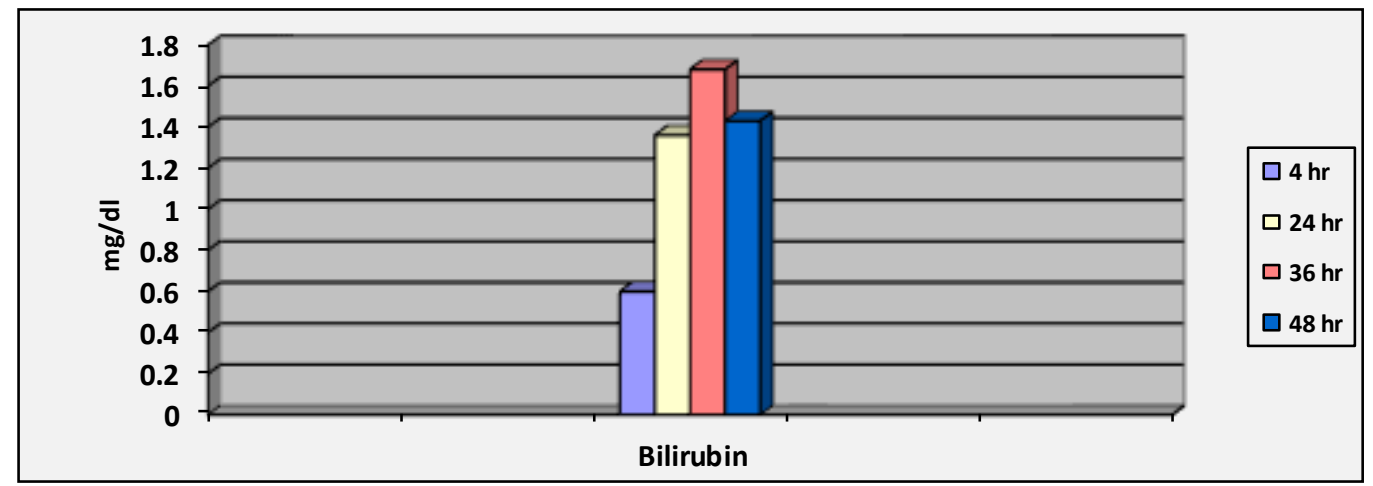

Fig. (2): Mean values of serum total bilirubin of acute paracetamol intoxicated patients at different hours post-ingestion.

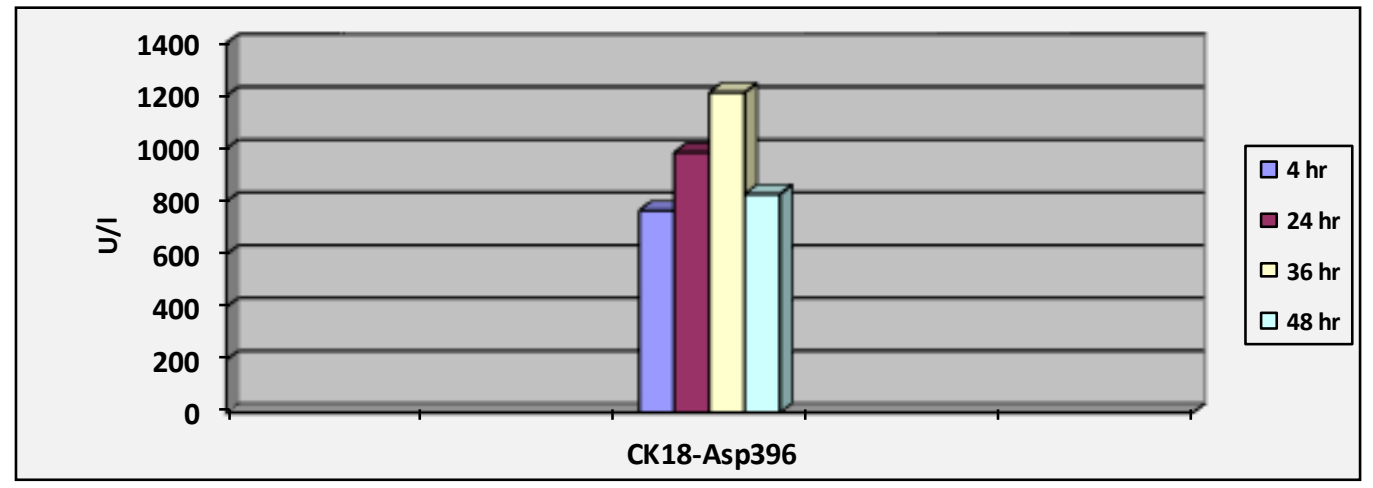

Fig. (3): Mean values of CK18-Asp396 of acute paracetamol intoxicated patientsat different hours post-ingestion. 


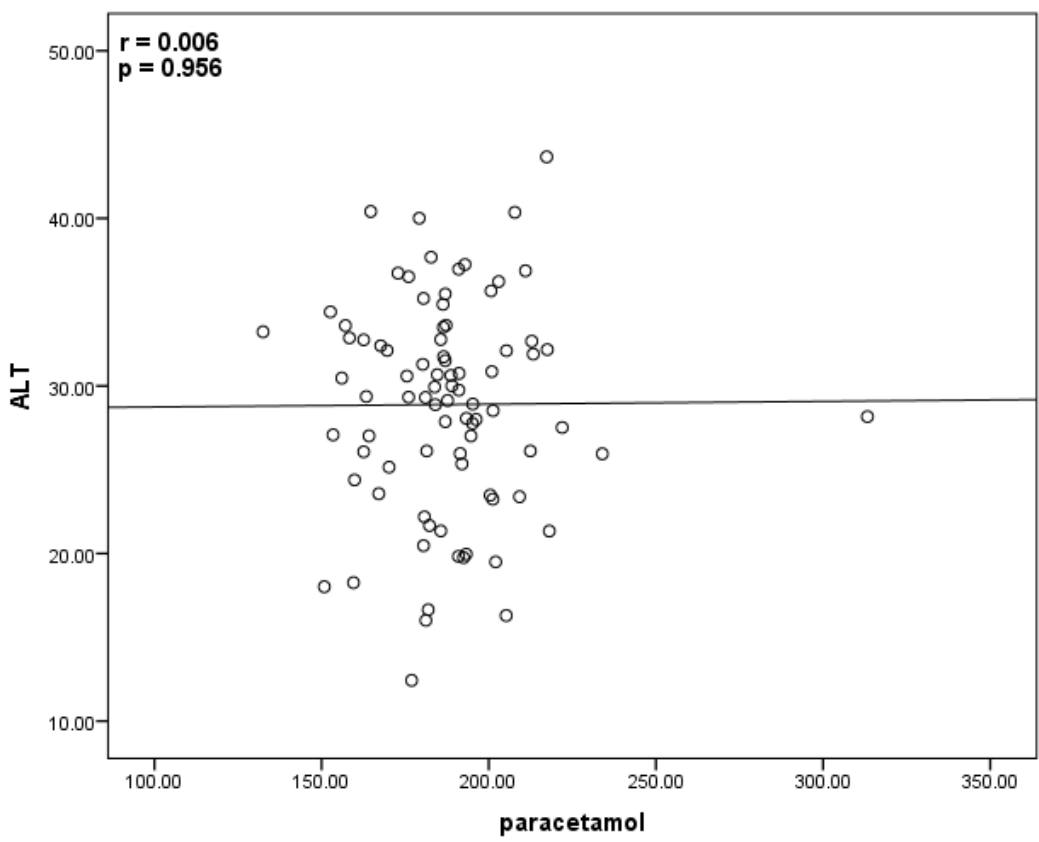

Fig. (4): Correlation graph betweenmean of paracetamol leveland ALT (alanine transferase) of acute paracetamol intoxicated patients 4 hours post-ingestion.

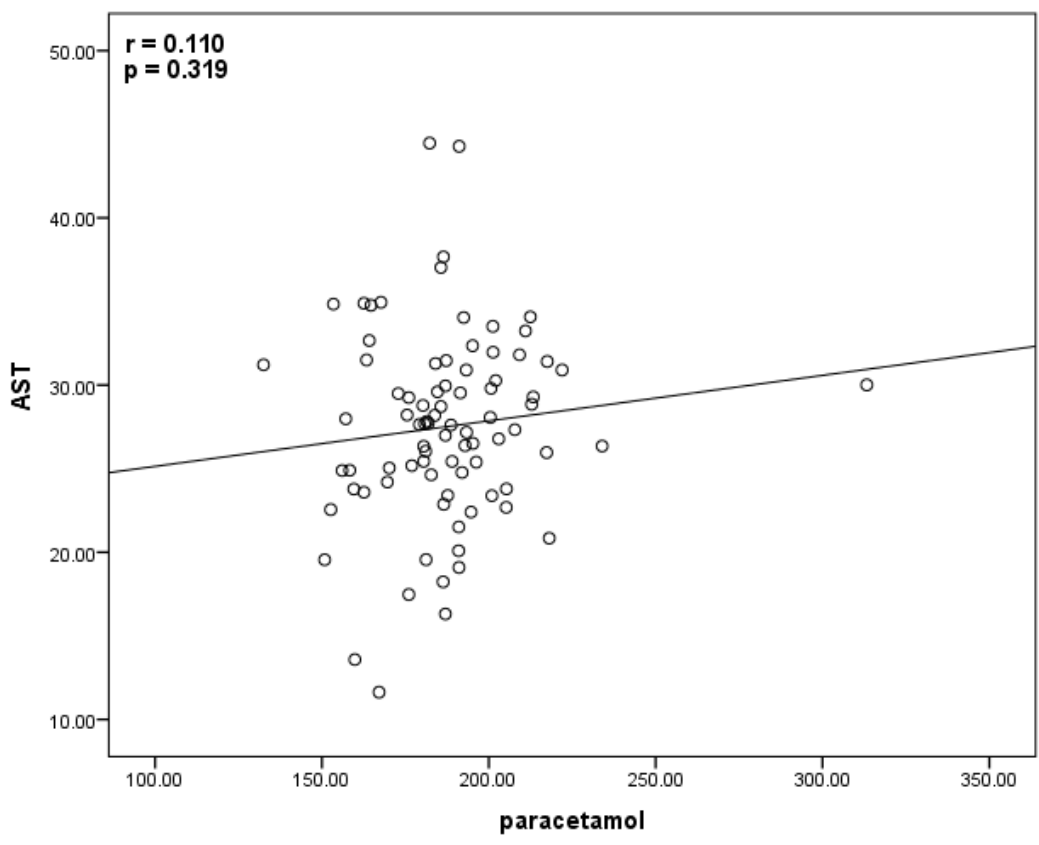

Fig. (5): correlation graph betweenmean of paracetamol leveland AST (aspartate transferase) of acute paracetamol intoxicated patients 4 hours post-ingestion. 


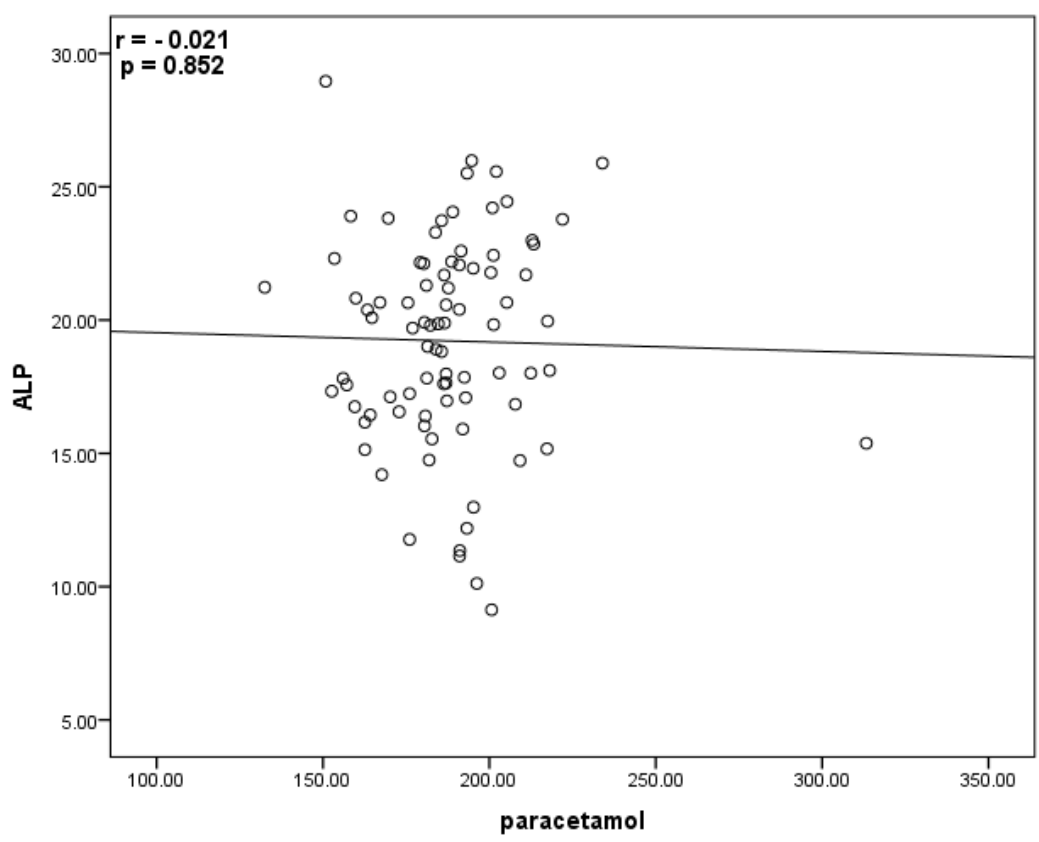

Fig. (6): correlation graph betweenmean of paracetamol leveland ALP (alkaline phosphatase) of acute paracetamol intoxicated patients 4 hours post-ingestion.

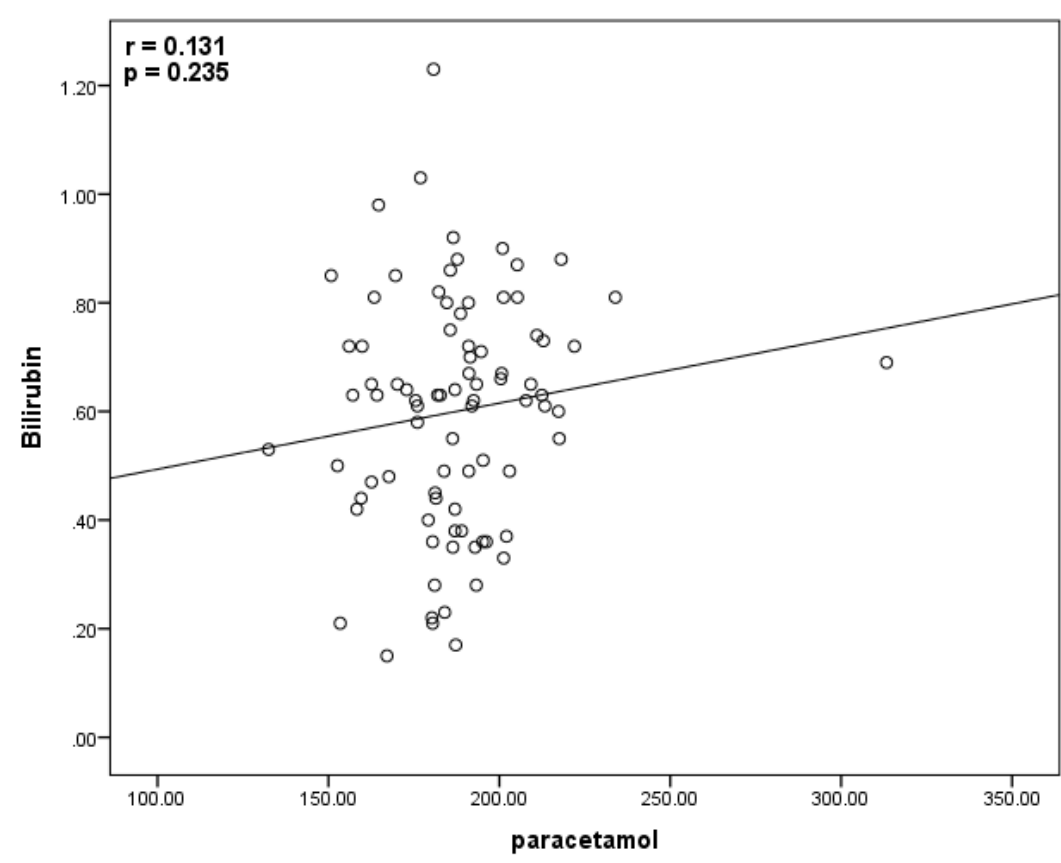

Fig. (7): correlation graph betweenmean of paracetamol leveland bilirubin of acute paracetamol intoxicated patients 4 hours post-ingestion. 


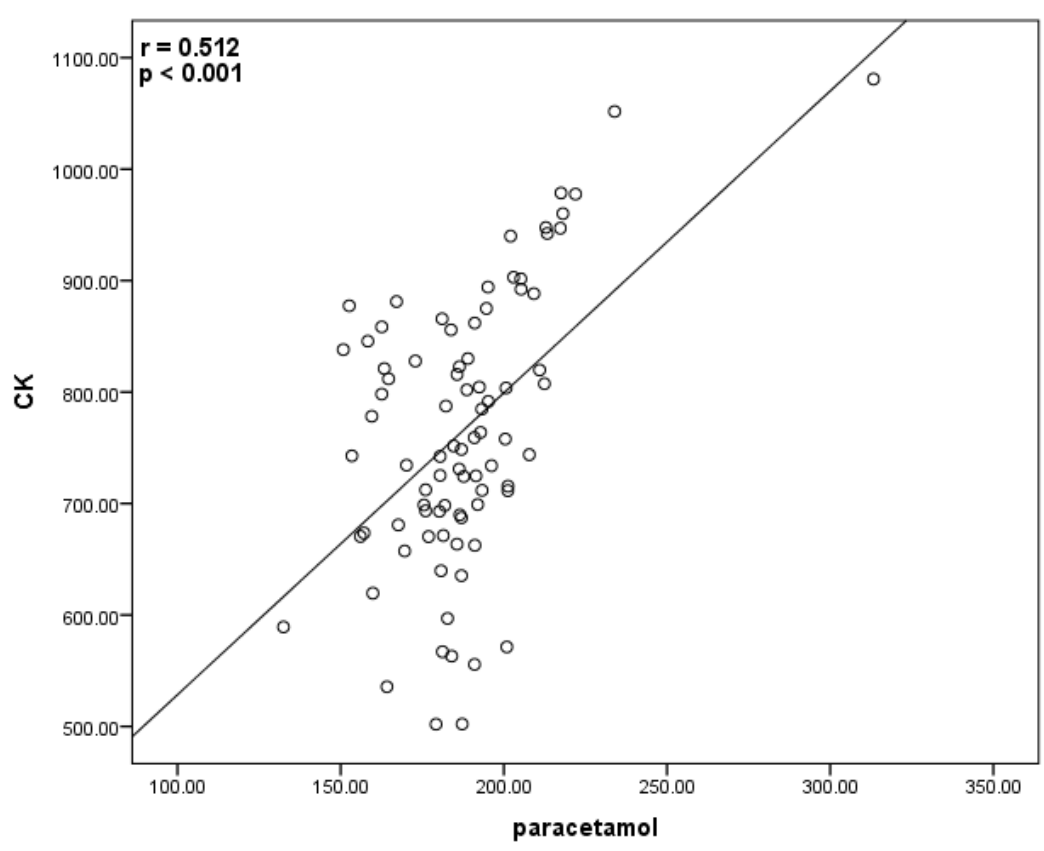

Fig. (8): correlation graph betweenmean of paracetamol level and CK18-ASP396 of acute paracetamol intoxicated patients 4 hours post-ingestion.

\section{Discussion}

Paracetamol (acetaminophen) toxicity remains theleading cause of acute liver failure in the developed world, accounting for over $40 \%$ of cases inselected case series (Ostapowicz et al., 2002).

As the liver enzymatic changes don't take place in the first 24 hours after ingestion of paracetamol(livertox.nih.gov), their use in the early assessment of the liver state is not accurate. Moreover, the translational multimechanistic events of APAP liver toxicity are well described and can be monitored with circulating mechanism-based biomarkers in human and murine models (Antoine et al., 2012and Antoine et al., 2013).

Accordingly, the current study was conducted to investigate that Cytokeratin 18Asp396can representan early and valuable predictor of pre-clinical and clinical acute paracetamol toxicity in humans.

The results of the current study revealed that all investigated liver function tests including ALT, AST, ALP and bilirubin started to be increased with statistically significant values after 24 hours post-ingestion, reached a peak after 36 hours, and started to decline after 48 hours. These findings are in accordance with many previous studies (Tsutsui et al., 2010andSoundharrajan et al., 2016). Basing on these findings, it could be concluded that the use of liver enzymes, as routinely done, to assess the liver state in early APAP-induced hepatotoxicity is not accurate. This could be explained by the fact that the process of increasing liver enzymes is a timeconsuming process that becomes evident after the disruption of mass hepatocytes membranes (Amacher, 1989).

On the other hand, it has been found that Cytokeratin 18-Asp396 values were increased significantly 4 hours post-ingestion, reached a peak after 36 hours, and started to decline after 48 hours. These findings are in agreement with Hofer et al., (2009), who stated that Cell death serum biomarkers are early predictors for survival in severe septic patients with hepatic dysfunction (http://ccforum.com/content/13/3/R93).

These findings could be explained by the well-established data that serum CK18Asp396 levels have been associated with apoptotic activity as assessed by TUNEL(Duan et al., 2003). After the initiation of apoptosis, CK18 is cleaved by caspases, releasing a neoepitope termed CK18-Asp396, which is specifically recognized by the M30 monoclonal antibody (Kramer et al., 2004). The specific proteolytic cleavage of CK18 is an event which occurs before the disruption of membrane asymmetry (Caulin et al., 1997).

\section{Conclusion}

In conclusion, Cytokeratin 18-Asp396may be used as an early and valuablepredictor of preclinical and clinical acute paracetamol toxicity in humans. To the best of our knowledge, this is the first report that the levels of apoptosisspecific epithelial cell-derived caspase-cleaved CK18 neoepitope, as detected by CK18- 
Asp396 ELISA, in patients with severe acute paracetamol hepatotoxicity. It is recommended to make another studies to assess sensitivity and specificity of CK18-Asp396 as an early predictor for acute paracetamolinducedhepatotoxicity.

\section{References}

Amacher DE(1998):Serum Transaminase Elevations as Indicators of Hepatic Injury Following the Administration of Drugs. RegulatoryToxicologyandPharmacolo gy, 27:119-130.

Antoine DJ, Jenkins RE, Dear JW, et al.,(2012): Molecular forms of HMGB1 and keratin-18 as mechanistic biomarkers for mode of cell death and prognosis during clinical acetaminophen hepatotoxicity. J Hepatol. 56:1070-1079.

Antoine DJ, Dear JW, Lewis PS, et al., (2013):Mechanistic biomarkers provide early and sensitive detection ofacetaminophen-induced acute liver injury at first presentation to hospital. HEPATOLOGY; 58:777-787.

Caulin C, Salvesen GS andOshima RG(1997): Caspase cleavage of keratin 18 and reorganization of intermediate $\mathrm{fi}$ laments during epithelial cell apoptosis. J Cell Biol.138: 1379-94.

Donald WM and Ralph H (1993): Methods of the determination of alkaline phosphatase activity and amino transeferases. In: Teitz Textbook of Clinical Chemistry. 2nd edition, WB Saunders Co., London PP. 788-832.

Duan WR, Garner DS, Williams SD et al., (2003): Comparison of immunohistochemistry for activated caspase-3 and cleaved cytokeratin 18 with the TUNEL method for quantification of apoptosis in histological sections of PC-3 subcutaneous xenografts. J Pathol. 199: 221-28.

Glynn JP and Kendal SE (1975): Letter: paracetamol measurement. Lancet.; 1:1147-8.

Hofer S, Brenner T, Bopp C, et al., (2009): Cell death serum biomarkers are early predictors for survival in severe septic patients with hepatic dysfunction. Critical Care Vol 13 No 3, Available online

http://ccforum.com/content/13/3/R93.

http://livertox.nih.gov/Acetaminophen. htm.Overview acetaminophenhepatotoxicity.

Clinical and research information on drug-induced liver injury at NLM (national library of medicine), USA.

Kind $\mathrm{P}$ and King E (1954): Estimation of plasma phosphatase by determination of hydrolysed phenol with aminoantipyrine. J. Clin. Path. 7: 322-326.

Kramer G, Erdal H, Mertens HJ et al., (2004): Differentiation between cell death modes using measurements of different soluble forms of extracellular cytokeratin 18. Cancer Res., 64: 1751-56 10.

Ostapowicz G, Fontana RJ, Schiodt FV, et al., (2002): Results of a prospective study of acute liver failure at 17 tertiary care centers in the United States. Ann Intern Med. 137: 947-54.

Reitman S and Frankel S (1957):Glutamateoxalate transaminase (GOT), Glutamate-pyruvate trans-aminase (GPT). Am. J. Clin. Path. 28:56-65.

Rumack BH and Matthew H (1975): Acetaminophen poisoning and toxicity. Pediatrics, 55 (6): 871-6.

Soundharrajan I, Naif A, Srisesharam S etal., (2016):Acetaminophen Induced Hepatotoxicity in Wistar Rats: A Proteomic Approach. Molecules, 21:161.

Suber RL (1994): Clinical pathology methods for toxicology. In: Hayes AW (ed.): Principles and methods of toxicology, 3rd edition, Raven Press, New York, pp. 476-96.

Tsutsui M, Tanaka N, Kawakubo M, et al.,(2010): Serum Fragmented Cytokeratin 18 Levels Reflect the Histologic Activity Score of Nonalcoholic Fatty Liver Disease More Accurately Than Serum Alanine Aminotransferase Levels. J ClinGastroenterol. 44(6):440-47.

Ueno T, Toi M, Bivén K et al., (2003): Measurement of an apoptotic product in the sera of breast cancer patients. Eur J Cancer, 39: 769-74.

Yagmur E, Trautwein C, Leers MP et al., (2007): Elevated apoptosis-associated cytokeratin 18fragments (CK18Asp386) in serum of patients with chronic liver diseases indicate hepatic and biliary inflammation. ClinBiochem. 40: 651-55. 


\section{الملخص العربيى}

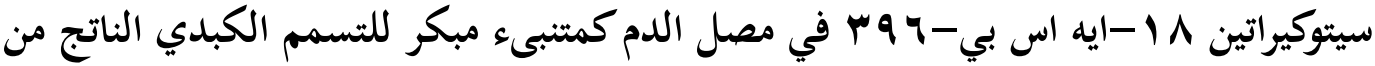 التسمم الحاد بالباراسيتامول كميثي مبكر}

\section{محمد عبد العظيم محمد خلف و أحمد حفناوي عباس و مصطفى أبو الحمد1}

يعد الباراسيتامول من الأدوية المعروفة المسببة للتسمم الكبدي في الجرعات الحادة الزائدة ولا يزال التقييم المبكر لشدة

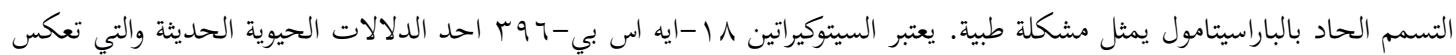

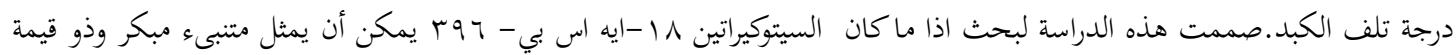

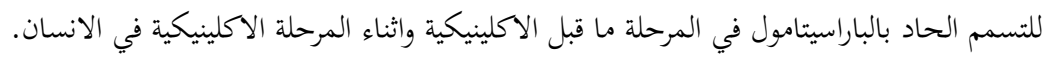

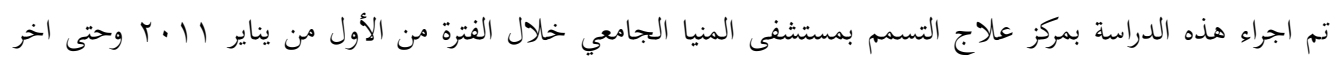

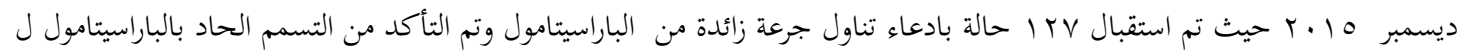

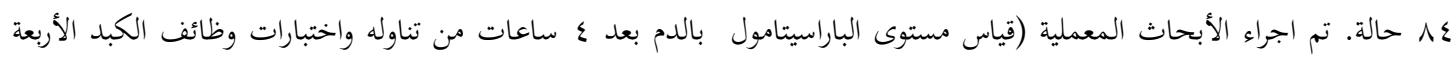

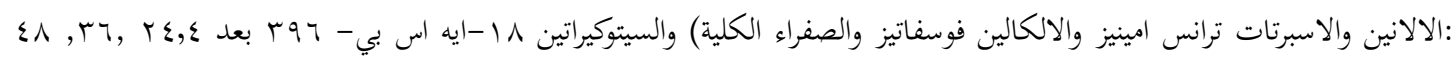
ساعة من تناوله. وقد أظهرت نتائج الدراسة الحالية أن وظائف الكبد بدأت في الزيادة وكانت هذه الزيادة ذو دلالة احصائية بعد ؟ب ساعة

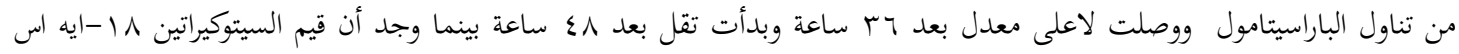

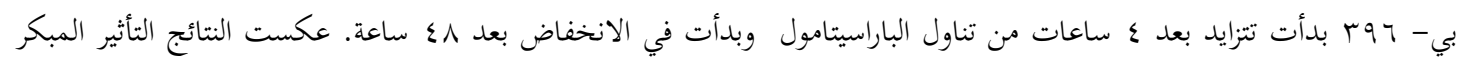

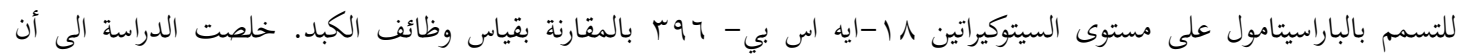

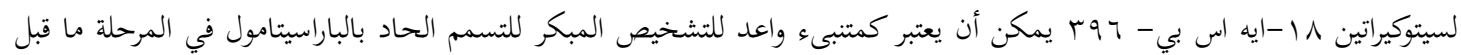

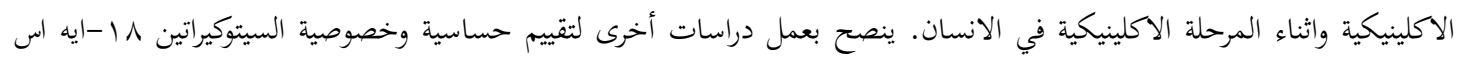
بي - 97 ب كمتنبى للتشخيص المبكر للتسمم الحاد بالباراسيتامول.

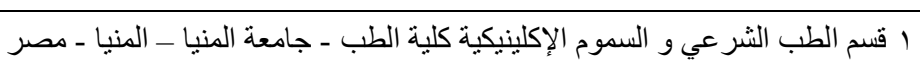

